Montreal, Quebec H3A 1A1, Canada.

97-OA-055. Vigeant P, Loo VG, Bertrand C, Dixon C, Hollis $R$, Pfaller MA, McLean PH, Briedis DJ, Perl TM, Robson HG. An outbreak of Serratia marcescens infections related to contaminated chlorhexidine. Infect Control Hosp Epidemiol 1998;19:791-794.

\section{REFERENCES}

1. Yu VL, Oakes CA, Axnick KJ, Merigan TC. Patient factors contributing to the emergence of gentamicin-resistant Serratia marcescens. Am J Med 1979;66:468-472.

2. Sautter RL, Mattman LH, Legaspi RC. Serratia marcescens meningitis associated with a contaminated benzalkonium chloride solution. Infect Control 1984;5:223-225.

3. Barry MA, Craven DE, Goularte TA, Lichtenberg DA. Serratia marcescens contamination of antiseptic soap containing triclosan: implications for nosocomial infection. Infect Control 1984;5:427 430.
4. McAllister TA, Lucas CE, Mocan H, Liddell RHA, Gibson BES, Hann IM, et al. Serratia marcescens outbreak in a paediatric oncology unit traced to contaminated chlorhexidine. Scot Med J 1989;34:525-528.

5. Pfaller MA, Hollis RJ, Sader HS. Chromosomal restriction fragment analysis by pulsed-field gel electropheresis. In: Isenberg HD, ed. Clinical Microbiology Procedures Handbook. American Society for Microbiology. Washington, DC; 1994 (suppl 1):10.5C.1-11.

6. Burdon DW, Whitby JL. Contamination of hospital disinfectants with Pseudomonas species. Br Med J 1967;2:153-155.

7. Rutala WA, Cole EC. Antiseptics and disinfectants: safe and effective? Infect Control 1984;5:215-218.

\title{
VRE in Chronic Hemodialysis Patients
}

\section{Gina Pugliese, RN, MS Martin S. Favero, PhD}

Vancomycin-resistant Enterococcus (VRE) has been identified with increased frequency in dialysis populations, but the risk factors for VRE colonization are not well defined in hemodialysis patients. Investigators from the University of Maryland School of Medicine conducted a study to determine such risk factors. Patients from a university-affiliated outpatient dialysis center had surveillance stool or rectal cultures for VRE obtained during April 1994 and January 1996. The combined cohort of 168 patients was followed up for all-cause mortality, subsequent hospitalization, and VRE infection. Demographic and risk factor information, including age, gender, race, diabetes, coronary artery disease, and human immunodeficiency virus infection were collected on all patients.
Sixteen patients had surveillance cultures grow vancomycin-resistant Enterococcus faecium or Enterococcus faecalis (VREF), and nine additional patients had clinical cultures positive for VREF. The median follow-up time for patients with positive surveillance or clinical cultures for VREF was 421 days versus 423 days for those without VREF

Patients with positive surveillance cultures for VREF had less time on hemodialysis before screening (median, 207 vs 822 days; $P<.01)$ and more hospitalization in the year before screening (median, 19 vs 3 days; $P<.01$ ) compared with those without VREF. Patients with VREF colonization were more likely to develop infection with VREF (25\% vs $1 \%$; $P<.01)$ than those without VREF colonization. However, adjusting for age, diabetes, coronary artery disease, and acquired immune deficiency syndrome using Cox proportional-hazards models, the presence of VREF on screening culture was not associated with an increased risk of death (RR, $1.1 ; P=.86)$. Thus, after adjusting for other comorbidities, VREF colonization was not associated with increased mortality.

Patients with end-stage renal disease on hemodialysis who are hospitalized are more likely to have VREF, but longer duration on hemodialysis was not associated with presence of this organism. This suggests that VRE transmission occurs predominantly in the inpatient setting.

FROM: Roghmann MC, Fink JC, Polish L, Maker T, Brewrink J, Morris JG $\mathrm{Jr}$, et al. Colonization with vancomycinresistant enterococci in chronic hemodialysis patients. Am J Kidney Dis 1998;32:254257. 